\title{
Degradation of CI-Inhibitor by Plasmin: Implications for the Control of Inflammatory Processes
}

\author{
Eleanor M. Wallace, ${ }^{1}$ Stephen J. Perkins, ${ }^{2}$ Robert B. Sim, ${ }^{3}$ \\ Anthony C. Willis, ${ }^{3}$ Con Feighery, ${ }^{1}$ and John Jackson ${ }^{1,4}$ \\ ${ }^{1}$ Department of Immunology, St. James' Hospital, Dublin 8, Ireland \\ ${ }^{2}$ Department of Biochemistry and Molecular Biology, Royal Free \\ Hospital School of Medicine, London, U.K. ${ }^{3}$ MRC Immunochemistry \\ Unit, Department of Biochemistry, University of Oxford, Oxford, \\ U.K. ${ }^{4}$ The Dublin Institute of Technology, Dublin, Ireland
}

\begin{abstract}
Background: A correct balance between protease and inhibitor activity is critical in the maintenance of homoeostasis; excessive activation of enzyme pathways is frequently associated with inflammatory disorders. Plasmin is an enzyme ubiquitously activated in inflammatory disorders, and $\mathrm{Cl}$-inhibitor $(\mathrm{Cl}-\mathrm{Inh})$ is a pivotal inhibitor of protease activity, which is particularly important in the regulation of enzyme cascades generated in plasma. The nature of the interaction between plasmin and Cl-Inh is poorly understood.

Materials and Methods: Cl-Inh was immunoadsorbed from the plasma of normal individuals $(n=21)$, from that of patients with systemic lupus erythematosus $(n=18)$ or adult respiratory distress syndrome $(n=9)$, and from the plasma and synovial fluid of patients with rheumatoid arthritis $(n=18)$. As plasmin is a putative enzyme responsible for $\mathrm{Cl}$-Inh degradation, the interaction between plasmin and $\mathrm{Cl}$-Inh was examined using SDS-PAGE. In addition, peptides cleaved from $\mathrm{Cl}$-Inh by plasmin were isolated and sequenced and the precise cleavage sites determined from the known primary sequence of $\mathrm{Cl}$-Inh. Homology models of $\mathrm{Cl}$-Inh were then constructed.
\end{abstract}

Results: Increased levels of cleaved and inactivated C1Inh were found in each of the inflammatory disorders examined. Through SDS-PAGE analysis it was shown that plasmin rapidly degraded $\mathrm{Cl}$-Inh in vitro. The pattern of Cl-Inh cleavage seen in vivo in patients with inflammatory disorders and that produced in vitro following incubation with plasmin were very similar. Homology models of $\mathrm{Cl}$-Inh indicate that the majority of the plasmin cleavage sites are adjacent to the reactive site of the inhibitor.

Conclusions: This study suggests that local C1-Inh degradation by plasmin may be a central and critical event in the loss of protease inhibition during inflammation. These findings have important implications for our understanding of pathogenic mechanisms in inflammation and for the development of more effectively targeted therapeutic regimes. These findings may also explain the efficacy of anti-plasmin agents in the treatment of $\mathrm{Cl}$ Inh deficiency states, as they may diminish plasminmediated C1-Inh degradation.

\section{INTRODUCTION}

Inflammation occurs as a result of the host's response to tissue injury and is a consequence of a complex series of interactions involving cellular and chemical mediators. The characteristic

Address correspondence and reprint requests to: John Jackson, Dept. of Immunology, Central Pathology, St. James Hospital, Dublin 8, Ireland. Tel: 014537941 Ext. 2921; Fax: 014545609. movement of fluid and white cells from blood into the extravascular tissues is the host's attempt to contain and eliminate damaged tissues, foreign particles, and microorganisms. The ultimate aim of this process is to limit damage and initiate tissue repair. If the effort to restore homeostasis is unsuccessful, inflammation may become harmful and lead to extensive tissue destruction and injury (1). This is well illustrated in many common inflammatory disorders, such as 
inflammatory bowel disease, rheumatoid arthritis (RA) and psoriasis and in other less common disorders such as systemic lupus erythematosus (SLE) and adult respiratory distress syndrome (ARDS) (1). An important prerequisite for a successful inflammatory response and a return to homeostasis is the effective control of damaging enzymes generated during inflammation (1). To this end, plasma protease inhibitors represent $10 \%$ of total plasma protein, controlling proteolytic events critical in the inflammatory response, such as those occuring during kinin, coagulation, fibrinolysis, and complement activation, as well as controlling the enzymes released from activated leucocytes $(2,3)$. Serine protease inhibitors (serpins) are an important family of inhibitors that play an essential role in the regulation of serine proteases generated during inflammatory processes (4). Their central role is underlined by deficiency states such as hereditary angioedema (C1-Inh deficiency) (5); emphysema ( $\alpha$-1-proteinase inhibitor deficiency) (6); recurrent hemorrage ( $\alpha$-2-anti-plasmin deficiency) (7); and thrombosis (antithrombin III deficiency) (8). Furthermore, serpins behave as acute phase proteins and their synthesis is increased in response to tissue damage (9).

$\mathrm{Cl}$-inhibitor (Cl-Inh) is a member of the serpin family that has a pivotal role in the control of proteases involved in the early phase of the inflammatory response. These proteases include proteins of the complement ( $\mathrm{Clr}$ and $\mathrm{Cls}$ ), kinin (plasma kallikrein), coagulation (factors XIa, XIIa and XIIf), and fibrinolytic (plasmin) pathways $(5,10)$.

Deficiency of C1-Inh leads to defective regulation of the inflammatory pathways and recurrent bouts of tissue swelling, or angioedema. These episodes of angioedema are thought to occur when $\mathrm{Cl}$-Inh is depleted to a critical level. Interestingly, Cl-Inh deficiency may be effectively treated with anti-plasmin agents, which suggests that plasmin activation is central to the pathogenesis of this disorder (10). Plasmin, an enzyme activated during many inflammatory processes, is important in controlling fibrin deposition in tissue, which is a very early response to tissue injury (11). Furthermore, fibrin deposition and plasmin activation are hallmarks of many common inflammatory disorders. $\mathrm{Cl}$-Inh is thought to inhibit plasmin according to the general mechanism of serpin action; however, little is known about the Cl-Inh/plasmin interaction $(2,3,10)$. Early studies investigating the nature of the $\mathrm{C} 1$-Inh/plasmin encounter observed that it is different from the serpin mechanism of protease inhibition (12-14).

In this study, we examined $\mathrm{Cl}$-Inh consumption and degradation in plasma from patients with a variety of inflammatory disorders as well as in plasma and synovial fluid from patients with active rheumatoid arthritis, and found increased levels of degraded, low molecular weight forms of $\mathrm{Cl}$-Inh. As plasmin is a putative enzyme involved in $\mathrm{Cl}$-Inh degradation, the interaction between $\mathrm{Cl}$-Inh and plasmin was examined in detail in vitro. Our results show that Cl-Inh is rapidly cleaved by plasmin at several sites in the molecule, resulting in inactivated $\mathrm{Cl}$-Inh. Furthermore, degraded forms of C1-Inh, which were similar to those generated in vitro, were found in the plasma of patients with inflammatory disorders.

Local depletion of C1-Inh by plasmin could contribute significantly to the pathogenesis of inflammatory conditions by altering the protease inhibitor balance. In addition, our results also provide an explanation for the efficacy of antiplasmin agents in the treatment of $\mathrm{Cl}$-Inh deficiency states. Finally, it is also suggested that proteolytic degradation of other serpins could be an important pathogenic mechanism in other inflammatory processes.

\section{MATERIALS AND METHODS}

\section{Examination of Cl-Inh Consumption and Degradation}

Blood from the following individuals was collected in siliconized vacutainer tubes to which EDTA $(10 \mathrm{mM})$ and polybrene $(0.05 \%, \mathrm{w} / \mathrm{v}) \mathrm{had}$ been added to prevent in vitro activation of the complement and the contact system: 21 normal controls, 24 individuals with SLE, 18 patients with RA, and 9 patients with ARDS. Paired synovial fluids from the same RA patients were collected in an identical manner. Plasma and synovial fluid supernatant were obtained by centrifugation and were immediately aliquoted and stored at $-70^{\circ} \mathrm{C}$. All processing was performed in plastic tubes. The plasma was thawed immediately before analysis. Cl-Inh was immunoadsorbed from plasma for analysis according to a previously published method (15). The various forms of immunopurified $\mathrm{Cl}$-Inh were separated by SDS-PAGE (nonreduced) and visualized by Western blotting. Native, cleaved, and complexed forms of C1-Inh were scanned and quantified by densitometry. 


\section{SDS-PAGE}

SDS-PAGE $(7.5 \%$ acrylamide) was performed according to the general method of Laemmli (16). The samples were added to an equal volume of sample buffer $(0.125 \mathrm{M}$ Tris, $8 \mathrm{M}$ urea, $4 \% \mathrm{w} / \mathrm{v}$ SDS, $20 \% \mathrm{v} / \mathrm{v}$ glycerol, $\mathrm{pH} 6.8)$. Protein bands were visualized using $0.1 \%(\mathrm{w} / \mathrm{v})$ Coomassie brilliant blue-R250 (CBB) in 40\% methanol (v/v) and 7\% acetic acid (v/v). The molecular mass of visible bands was determined by the electrophoresis of protein standards of known molecular mass (29 kDa-205 kDa: SDS-6H, Sigma).

\section{Purification of C1-Inhibitor}

$\mathrm{Cl}$-Inh was prepared from $200 \mathrm{ml}$ of fresh frozen plasma using a modification of previously published procedures $(17,18)$. All procedures were performed at $4^{\circ} \mathrm{C}$. Fractions were monitored for the presence of $\mathrm{Cl}$-Inh by rocket electrophoresis with a polyclonal rabbit anti-human Cl-Inh antibody (Dako). Fresh frozen plasma was made $0.01 \mathrm{M}$ with EDTA and benzamidine (Sigma) and was made $1 \mathrm{mM}$ with phenylmethylsulfonyl fluoride (PMSF; Sigma). A stock solution of polybrene in EDTA $(12.5 \mathrm{ml})$ was then added to produce final polybrene and EDTA concentrations of $1.2 \mathrm{mg} / \mathrm{ml}$ and $20 \mathrm{mM}$, respectively. The plasma was adjusted to $\mathrm{pH} 7.0$ and chilled to $4^{\circ} \mathrm{C}$. Solid polyethylene glycol 4000 was added all at once, resulting in a final concentration of $5 \%$ $(\mathrm{w} / \mathrm{v})$, and stirred for $\mathrm{l} \mathrm{hr}$. The precipitate was removed by centrifugation for $30 \mathrm{~min}$ at $10,000 \times g$. The supernatant was mixed with PMSF to make a $1 \mathrm{mM}$ final concentration and applied to a lysine-Sepharose column $(2.6 \times 9.5$ $\mathrm{cm}$ ) (Pharmacia) to remove plasminogen (19). All of the unadsorbed protein was pooled, mixed with PMSF to make a $1 \mathrm{mM}$ solution, equilibrated with $20 \mathrm{mM}$ sodium phosphate, $50 \mathrm{mM}$ $\mathrm{NaCl}, 5 \mathrm{mM}$ EDTA, $\mathrm{pH} \mathrm{7.0,} \mathrm{and} \mathrm{applied} \mathrm{to} \mathrm{a}$ column of Q-Sepharose $(20 \times 2.6 \mathrm{~cm})$ (Pharmacia) that was equilibrated with the same buffer. C1-Inh was eluted using a linear gradient $(500$ $\mathrm{ml}$ ) made from starting buffer and the same buffer made $300 \mathrm{mM}$ with $\mathrm{NaCl}$. Fractions containing $\mathrm{Cl}$-Inh were pooled, made $1 \mathrm{mM}$ with PMSF dialyzed against $20 \mathrm{mM}$ Tris- $\mathrm{HCl}, 100 \mathrm{mM}$ $\mathrm{NaCl}, \mathrm{pH} \mathrm{8.0}$, and applied to a column of Concanavalin A (Con-A)-Sepharose $(8 \times 5 \mathrm{~cm})$ (Pharmacia) that was equilibrated in the same buffer. Elution was achieved with starting buffer made $0.5 \% \quad(\mathrm{w} / \mathrm{v})$ with $\alpha$-methylmannoside
(Sigma). The final pool of $\mathrm{Cl}$-Inh was dialyzed against $20 \mathrm{mM}$ Tris- $\mathrm{HCl}, 100 \mathrm{mM} \mathrm{NaCl}, \mathrm{pH} 8.0$, and stored at $-70^{\circ} \mathrm{C}$. The concentration of $\mathrm{Cl}$ Inh in the final preparation $(0.16 \mathrm{mg} / \mathrm{ml})$ was determined at $280 \mathrm{~nm}$, assuming $\mathrm{E}^{1} \%(280 \mathrm{~nm})$ of 3.6 and a molecular mass of $105 \mathrm{kDa}$ (18). The discrepancy between the calculated molecular weight of Cl-Inh determined from sequence data and that from SDS-PAGE analysis probably reflects the heavily glycosylated nature of $\mathrm{Cl}$ Inh; this is further discussed by Perkins et al. (20). In addition, there is a further disparity between the apparent molecular weight of $\mathrm{Cl}$-Inh determined by SDS-PAGE, depending on the presence $(105 \mathrm{kDa})$ or absence $(115 \mathrm{kDa})$ of reducing agents.

\section{Purification of Activated Cls}

Activated $\mathrm{Cls}$ was isolated from fresh serum and stored at $-70^{\circ} \mathrm{C}(21)$.

\section{Functional Activity of Cl-Inh Purified from Plasma}

The functional activity of $\mathrm{Cl}$-Inh was assessed by examining its ability to form stable complexes with the protease Cls. Equimolar amounts of $\mathrm{Cl}$-Inh $(0.16 \mathrm{mg} / \mathrm{ml})$ and activated $\mathrm{Cls}$ were incubated together at $37^{\circ} \mathrm{C}$ in $0.02 \mathrm{M}$ sodium phosphate, $100 \mathrm{mM} \mathrm{NaCl}, \mathrm{pH} 7.2$ (PBS). At the end of 15- and 30-min incubation periods, identical aliquots (approximately $10 \mu \mathrm{g}$ total protein) were incubated with nonreducing sample buffer and boiled for $4 \mathrm{~min}$. These samples were analyzed by $7.5 \%$ SDS-PAGE and stained with CBB.

\section{Purification of Plasminogen}

Plasminogen was isolated from outdated plasma by lysine-Sepharose affinity chromatography and stored at $-70^{\circ} \mathrm{C}(19)$. Just before use, plasminogen was activated by incubating it with streptokinase (Sigma) at $37^{\circ} \mathrm{C}$ for $120 \mathrm{~min}$, using a molar ratio of 200:1 plasminogen to streptokinase. The plasminogen was fully activated by streptokinase as visualized by $7.5 \%$ SDS-PAGE of reduced and nonreduced samples (results not shown).

\section{Interaction of Cl-Inh with Plasmin and Cls in Vitro}

Equimolar quantities of $\mathrm{Cl}-\mathrm{Inh}(0.16 \mathrm{mg} / \mathrm{ml})$ were incubated separately with plasmin $(0.35$ 
$\mathrm{mg} / \mathrm{ml})$ or $\mathrm{Cls}(0.06 \mathrm{mg} / \mathrm{ml})$ at $37^{\circ} \mathrm{C}$ in PBS. At the end of 15- and 30-min incubation periods, identical aliquots of inhibitor and protease were incubated with nonreducing sample buffer, separated by $7.5 \%$ SDS-PAGE, and visualized with CBB.

\section{Time Course of the Cl-Inh/Plasmin Interaction: SDS-PAGE Analysis}

$\mathrm{Cl}$-Inh inactivates its target proteases through the formation of equimolar stoichiometric complexes between inhibitor and protease. Therefore, equimolar quantities of C1-Inh $(0.16 \mathrm{mg}$ / $\mathrm{ml})$ and plasmin $(0.35 \mathrm{mg} / \mathrm{ml})$ were incubated under physiological conditions at $37^{\circ} \mathrm{C}$ in PBS. At varying time intervals $(10 \mathrm{sec}, 5,15,45$, and 120 min), identical aliquots, calculated to contain approximately $10 \mu \mathrm{g}$ of inhibitor and protease, were added to an equal volume of sample buffer and boiled for $4 \mathrm{~min}$. The following controls were included: Cl-Inh in PBS, and plasmin in PBS. These samples were then subjected to $7.5 \%$ SDS-PAGE under nonreducing conditions and stained with CBB.

\section{Isolation of Peptides Generated from Cl-Inh by Plasmin Using HPLC}

C1-Inh $(0.16 \mathrm{mg} / \mathrm{ml})$, plasmin $(0.35 \mathrm{mg} / \mathrm{ml})$, and $\mathrm{Cl}$-Inh/plasmin (molar ratio 8:1 inhibitor to enzyme) were incubated in PBS, $\mathrm{pH} 7.2$, at $37^{\circ} \mathrm{C}$ for $60 \mathrm{~min}$. At the end of this incubation period, each preparation was acidified with $\mathrm{HCl}$ to $\mathrm{pH}$ 4.5 to prevent further proteolysis.

The peptides generated from the $\mathrm{Cl}$-Inh/ plasmin interaction were purified on a Vydac $\mathrm{C} 4$ column $(150 \times 2 \mathrm{~mm})$ equilibrated in $0.1 \% \mathrm{v} / \mathrm{v}$ trifluoroacetic acid, $2 \%$ v/v acetonitrile. Peptides were eluted with a linear gradient of $2-50 \% \mathrm{v} / \mathrm{v}$ acetonitrile applied over $50 \mathrm{~min}$ and then a further linear gradient of $50-90 \%$ acetonitrile over $18 \mathrm{~min}$. The samples were run on a Severn Analytical HPLC system consisting of a gradient controller utilizing Flowmaster software, two model SA6410B high-pressure pumps, and a model SA6504 detector fitted with a microbore flowcell. All detection was performed at E215 and data were collected using Waters' Expert Ease software from Millipore (Watford, U. K.).

\section{N-terminal Sequencing of C1-Inh Peptides}

The HPLC profiles for C1-Inh, plasmin, and each of the C1-Inh/plasmin mixtures were compared,

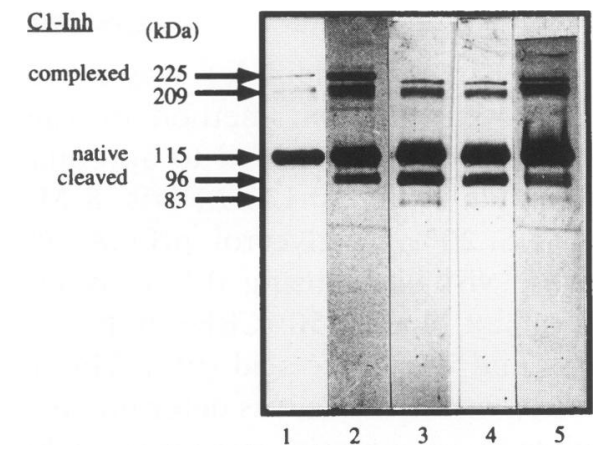

FIG. 1. C1-Inh consumption in plasma of a normal individual and of patients with the inflammatory conditions SLE, ARDS, and RA and in the synovial fluid of a patient with RA $\mathrm{Cl}$-Inh consumption and degradation was visualized by immunoblotting for $\mathrm{Cl}$-Inh which revealed native (115 kDa), cleaved (96 and $83 \mathrm{kDa}$ ), and complexed $\mathrm{Cl}$-Inh (225 and $209 \mathrm{kDa})$ : normal plasma (lane 1); SLE plasma (lane 2); ARDS plasma (lane 3); RA plasma (lane 4); RA synovial fluid (lane 5). Native, cleaved, and complexed C1-Inh were scanned and quantified by densitometry. Lanes 2-5 represent samples with relatively large amounts of cleaved or complexed C1-Inh.

and protein peaks not found in $\mathrm{Cl}$-Inh or plasmin alone were selected for $\mathrm{N}$-terminal sequencing.

All samples were run on an Applied Biosystems (ABI) 470A protein sequencer with on-line PTH analyzer. The samples were applied to a glass fiber disc pretreated with polybrene to limit sample wash-out and were run using the standard 03CPTH program from Applied Biosystems.

\section{C1-Inhibitor Modeling}

Protein structures were visualized through the INSIGHT 1195.0 program (Biosym/MSI, San Diego, CA) on Silicon Graphics INDY workstations. The rigid body fragment assembly method used in HOMOLOGY was used to construct an atomic model for the Cl-Inh serpin fold based on the uncleaved structure seen in ovalbumin (Brookhaven code lova: molecule $\mathrm{A}$ ) and the reactive-site cleaved structure of $\alpha_{1}$-antitrypsin (7api), together with the multiple-sequence alignment based on three known serpin crystal structures (22). After the definition of a protein core of 326 residues in ovalbumin, the remaining 39 residues in loop regions were constructed from a database of Brookhaven database fragments, and all of the side chains were replaced with those in C1-Inh. Energy refinements using 


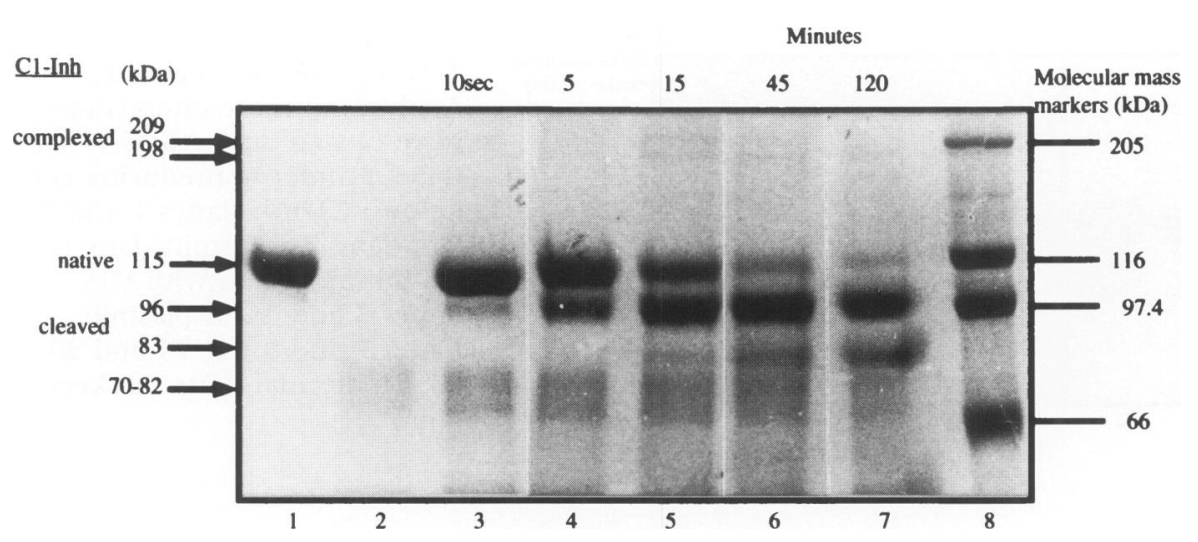

FIG. 2. Time course of the interaction of Cl-Inh with plasmin

$\mathrm{Cl}$-Inh and plasmin were incubated together at $37^{\circ} \mathrm{C}$ in PBS and aliquots containing $10 \mu \mathrm{g}$ were removed at time intervals from $10 \mathrm{sec}$ to 120 min and analyzed by $7.5 \%$ SDS-PAGE under nonreducing conditions and stained with Coomassie brilliant blue: C1-Inh (lane 1); plasmin (lane 2); $\mathrm{Cl}$-Inh incubated with plasmin for 10 sec, 5, 15, 45, and $120 \mathrm{~min}$ (lanes 3 to 7 ); molecular mass markers (lane 8 ).
DISCOVER were performed at the loop-splice junctions, then on the loop regions, and finally, the mutated core residues. The refinements improved the connectivity of the model and reduced the proportion of bad contacts or stereochemistry, as confirmed by the use of PROCHECK (23). Solvent accessibitility calculations were performed by the method of Lee and Richards (24).

\section{Statistical Analysis}

Analysis of variance (ANOVA) was used to test for differences in the levels of $\mathrm{Cl}$-Inh consumption between normal and patient groups. Using the estimate of pooled variance from the ANOVA, the following unpaired $t$-tests were performed: normal plasma and SLE plasma; normal plasma and ARDS plasma; normal plasma and RA plasma; and normal plasma and RA synovial fluid. A $p$-value of $\leqq 0.05$ indicated a significant difference.

\section{RESULTS}

\section{C1-Inh Consumption and Degradation in Normal, SLE, RA, and ARDS Plasma}

$\mathrm{Cl}$-Inh was found in three forms in the plasma of normal individuals: native $\mathrm{Cl}$-Inh $(115 \mathrm{kDa})$, cleaved $\mathrm{Cl}$-Inh $(96 \mathrm{kDa})$, and a high molecular weight form that probably represents $\mathrm{Cl}$-Inh complexed with proteases $(209-225 \mathrm{kDa})$. These species of $\mathrm{Cl}$-Inh were distinguished on the basis of their apparent molecular weight (nonreduced) in SDS-PAGE. In the plasma of patients with SLE [mean (percentage of total C1-Inh circulating in cleaved and/or complexed form) $=$ $24.6 \%, p<0.001$ ], ARDS (mean $=34.1 \%, p<$ 0.001 ), and RA (mean $=26.5 \%, p<0.001)$, and in the synovial fluid of patients with RA (mean $=$ $25.5 \%, p<0.001$ ), there was an increase in the proportion of $\mathrm{Cl}$-Inh circulating in the cleaved and/or complexed forms in comparison with normal plasma (mean $=12.7 \%$ ). Furthermore, an additional lower molecular weight form of $\mathrm{Cl}$-Inh was also observed migrating at $83 \mathrm{kDa}$ in the majority of plasma samples from patients with ARDS and in the synovial fluid of patients with RA. Analysis of a representative plasma sample from a normal individual, a patient with lupus, or ARDS, and of plasma and synovial fluid from a patient with RA is illustrated in Fig. 1.

To assess the role of plasmin in this Cl-Inh degradation, $\mathrm{Cl}$-Inh was incubated with plasmin in vitro and the reaction products were monitored by SDS-PAGE.

\section{Interaction of Cl-Inh with Plasmin or Cls}

The incubation of $\mathrm{Cl}$-Inh with plasmin ( $10 \mathrm{sec}-$ $120 \mathrm{~min}$ ) resulted in a reduction in the amount of native $\mathrm{Cl}$-Inh at $115 \mathrm{kDa}$ and the appearance of new major bands at $96 \mathrm{kDa}$ and $83 \mathrm{kDa}$. $\mathrm{Cl}$-Inh complexed with plasmin was only observed in trace amounts, at $209 \mathrm{kDa}$ and $198 \mathrm{kDa}$ (Fig. 2). (This interaction is compared with that of C1-Inh and C1s in Fig. 3.) In contrast to its interaction with plasmin, the interaction of $\mathrm{Cl}$ Inh with $\mathrm{Cls}$ results in the appearance of a high molecular weight complex at $225 \mathrm{kDa}$ (C1-Inh complexed with $\mathrm{Cls}$ ). The interaction of $\mathrm{Cl}$-Inh 


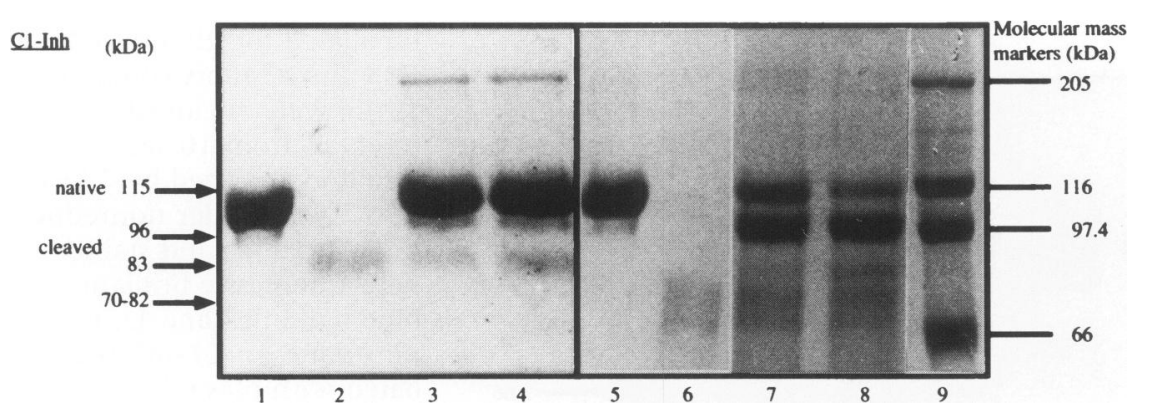

FIG. 3. Interaction of $\mathrm{Cl}$ Inh with plasmin and $C 1 s$ Cl-Inh was incubated separately with plasmin or Cls at $37^{\circ} \mathrm{C}$ in PBS for 15 and $30 \mathrm{~min}$. Analyses of these interactions were carried out by SDS-PAGE $(7.5 \%)$ under nonreducing conditions: $\mathrm{Cl}$-Inh (lanes 1 and 5); Cls (lane 2); plasmin (lane 6); $\mathrm{Cl}$-Inh incubated with $\mathrm{Cls}$ (lanes 3 and 4), or plasmin (lanes 7 and 8) for 15 and 30 min; molecular mass markers (lane 9). with $\mathrm{Clr}$ also results in the generation of complexed inhibitor and protease (results not shown).

\section{HPLC Analysis of C1-Inh/Plasmin Interaction: Profiles}

Figure 4 illustrates the reverse-phase HPLC profiles of C1-Inh, plasmin, and C1-Inh/plasmin (molar ratio 8:1 inhibitor to enzyme) that were incubated together at $37^{\circ} \mathrm{C}$ for $60 \mathrm{~min}$. Initially, $\mathrm{Cl}$-Inh and plasmin were incubated in equimolar amounts resulting in extensive digestion of Cl-Inh. The reaction was therefore limited by incubating $\mathrm{Cl}$-Inh in an inhibitor/plasmin ratio of 8:1. Peptide peaks not present in either plasmin or C1-Inh alone were selected for amino acid sequence analyses (Fig. 4).

\section{N-terminal Sequence Analysis of Peptides Generated from C1-Inh by Plasmin}

The amino acid sequences obtained from the selected HPLC protein peaks are detailed in Table 1.

The sites at which C1-Inh is cleaved to produce these peptides are indicated in Fig. 5. Numbering is according to Bock et al. (25) i.e., from the N-terminus of the mature protein. Glycosylated amino acids are indicated by black dots.

\section{Modeling Studies}

Homology modeling of the serpin fold in Cl-Inh was based on the sequence alignment with the structure of uncleaved ovalbumin (22). The conversion of ovalbumin to C1-Inh involved the

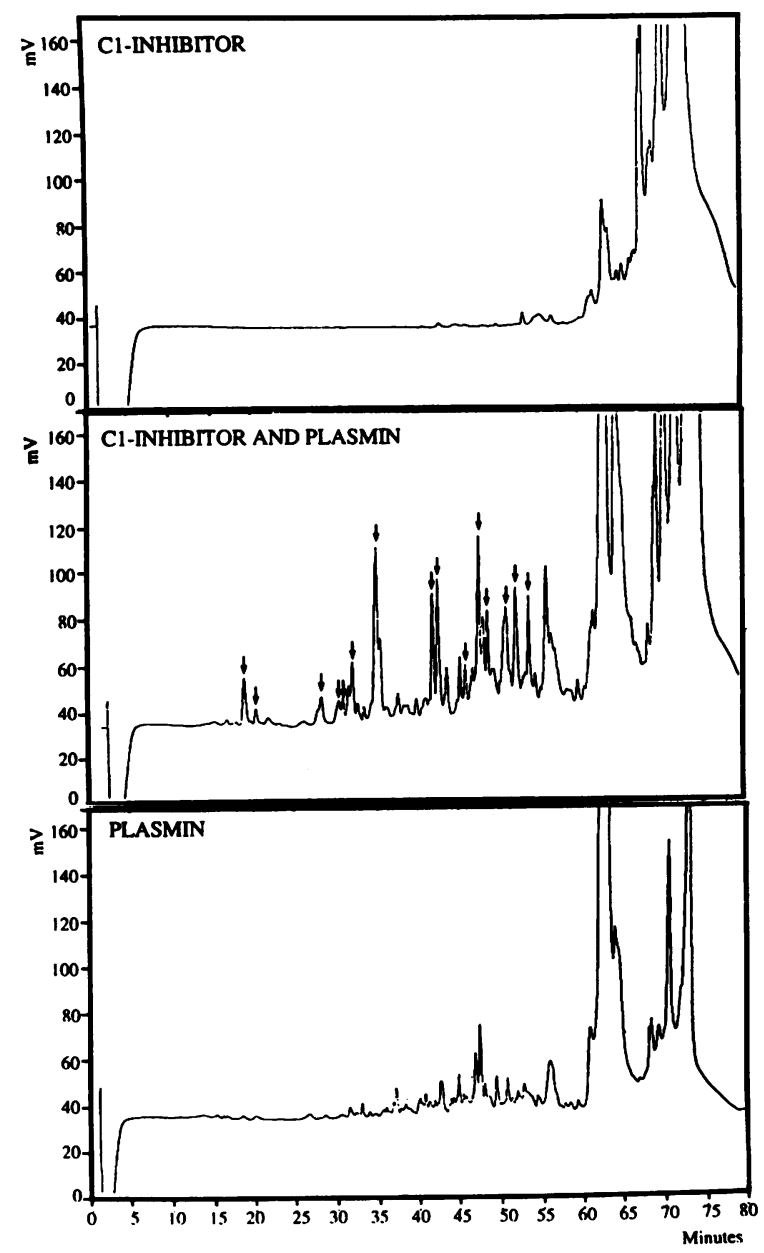

FIG. 4. HPLC profiles of the C1-Inh/plasmin interaction products

C1-Inh, C1-Inh and plasmin (8:1), and plasmin incubated at $37^{\circ} \mathrm{C}$ for 60 min were analyzed by reverse phase HPLC as described in Materials and Methods. Peptide peaks not present in C1-Inh or plasmin alone were selected for sequencing and are indicated by arrows. 
TABLE 1. Peptides Generated from Cl-Inh by Plasmin

\begin{tabular}{llll}
\hline Peptide no. & Peptide sequence & $\begin{array}{c}\text { C1-Inh cleavage sites } \\
\text { (amino acids) }\end{array}$ & $\begin{array}{c}\text { Location in } \\
\text { C1-Inh model }\end{array}$ \\
\hline N-terminal & NP-ATSSSSQDPESL & & $\alpha$-helix D \\
1 & GVTSVSQI & Residue 194-195(KG) & Loop \\
2 & KTRMEPFHFK & Residue 284-285(KK) & Loop \\
3 & TRMEPFHFK & Residue 285-286(KT) & Loop \\
4 & MEPFHFK & Residue 287-288(RM) & Loop \\
5 & NSVIKV & Residue 294-295(KN) & $\beta$-sheet C (strand 3) \\
6 & KYPVAHFIDQ & Residue 306-307(KK) & $\beta$-sheet B (strand 2) \\
7 & AKVGQLQLS & Residue 319-320 (KA) & Loop \\
8 & VGQLQLSHNL & Residue 321-322(KV) & $\alpha$-helix H \\
9 & HRLEDMEQAL & Residue 342-343(KH) & Residue 359-360 (KA)
\end{tabular}

Cleavage sites that generate these peptides are indicated. Numbering is according to Bock et al. (25), i.e., from the N-terminus of the circulating protein. Glycosylated amino acids are indicated by a hyphen.

deletion of two (10-residue and 11 -residue) surface regions in ovalbumin together with four minor 1 - and 2-residue deletions. Peptide mainchain breaks were annealed by energy refinements. Evidence that the model is satisfactory was provided by the surface locations of loop deletions, three carbohydrate sites at Asn216, Asn231, and Asn330, and the Cys residues Cys 183 and Cys406 that form interdomain disulphide bridges with the $\mathrm{N}$-terminus of $\mathrm{Cl}$-Inh. The model shows that 37 lysine and arginine residues are evenly distributed in the serpin fold of $\mathrm{Cl}$-Inh (Fig. 6A). Of the 10 plasmin cleavage sites in Table 1, 9 correspond to residues located at the end of the structure close to the reactive site loop in the uncleaved serpin fold (Fig. 6A). Lys 194 is the tenth cleavage site and is located in the central region of the serpin fold next to the 11 -residue deletion site. All 10 lysine and arginine residues were solvent accessible to varying degrees and all are sufficiently exposed for proteolysis by plasmin.

\section{DISCUSSION}

The damaging potential of inflammatory processes is dictated largely by the equilibrium between proteases and their inhibitors. The serpins are a family of inhibitors that regulate proteolytic

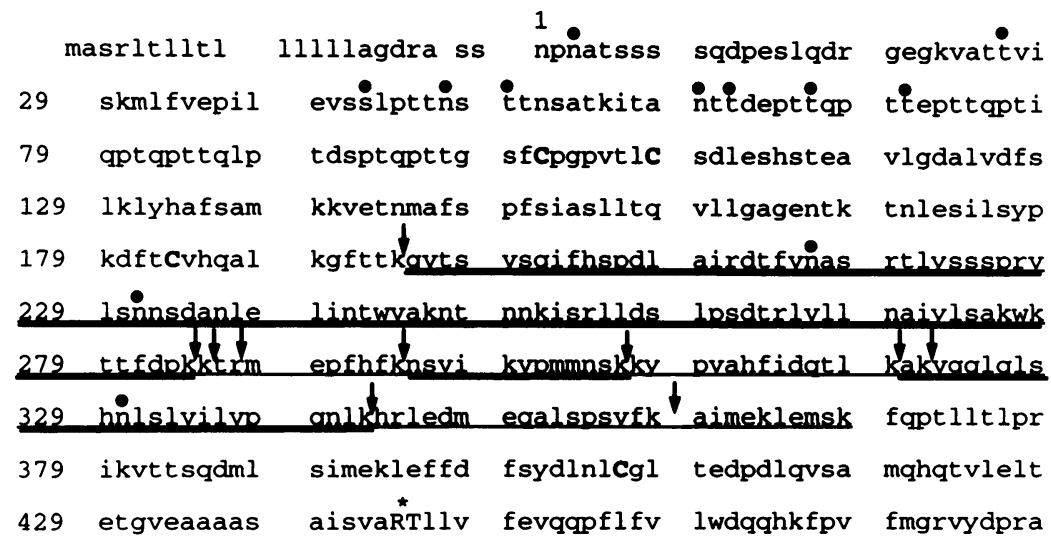

FIG. 5. C1-Inh cleavage sites after incubation with plasmin

Plasmin cleavage sites are indicated by arrows. Single and double underlining represent the different peptides generated from sequence data on cleavage products. Reactive site residues are in uppercase and indicated by $\left({ }^{*}\right)$, glycosylation sites by $(0)$, and cys 1 linked to cys 4 , cys 2 to cys 3 are represented by uppercase bold letters. 

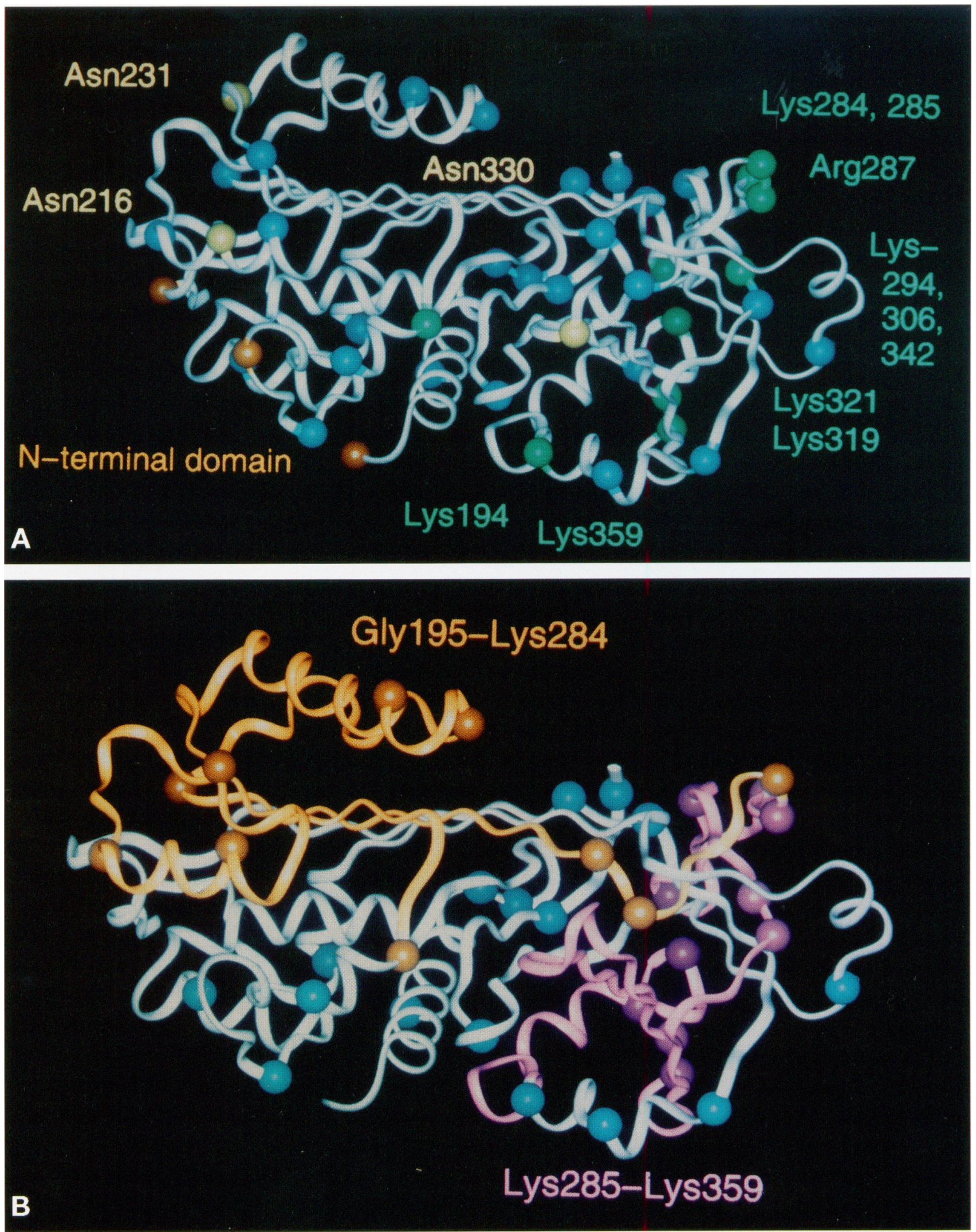

FIG. 6. Models of C1-Inh cleavage sites

(A) The homology-modeled serpin fold is denoted as a ribbon on which all $37 \alpha$-carbon atoms of Lys and Arg residues appear as blue and green spheres. The structure is viewed in the same orientation as Fig. 2 of Perkins (16). On the right, the 10 green spheres correspond to the proteolysis sites listed in Table 1, as identified by residue labeling. On the left, three orange spheres indicate the $\alpha$-carbon atoms of Glu 117, Cys 182, and Cys 406 which define the location of the major glycosylated $\mathrm{N}$-terminal extension of $\mathrm{Cl}$-Inh relative to the serpin fold (16). The location of three yellow spheres indicates the positions of glycosylation sites at Asn 216, Asn 231, and Asn 330. (B) The peptide released by cleavage between Gly 195 and Lys284 is marked in yellow while that between Lys 285 and Lys 359 is marked in purple. The structure is viewed at the same orientation as in A above. In (A) and (B), the reactive site loop in a helical conformation is located at the far right of the model as shown. 
activity generated by the homeostatic pathways of coagulation, fibrinolysis, complement, and kinin pathways or by proteases released from tissues during inflammatory processes (4). Activation of these pathways is a hallmark of many inflammatory disorders and contributes significantly to tissue damage in these situations. For example, the persistent inflammation and tissue damage observed in the joint in rheumatoid arthritis is partly mediated by the accumulation of the products of complement and coagulation activation (26). For these reasons an important goal of the acute phase response is to limit proteolysis by increasing the availability of serpins (9). Local serpin depletion could therefore have dramatic effects on the control of many physiological processes.

As $\mathrm{Cl}$-Inh is a pivotal inhibitor controlling several inflammatory pathways, a polyclonal antibody capture assay was established to examine $\mathrm{Cl}$-Inh consumption in vivo by measuring the relative amounts of native, cleaved, and complexed inhibitor circulating in plasma (15). ClInh consumption was examined in the plasma from 21 normal individuals, 24 individuals with SLE, 9 individuals with ARDS, and the paired plasma and synovial fluid of 18 patients with RA. It was found that $\mathrm{Cl}$-Inh circulates in three forms in normal plasma: native, cleaved, and complexed inhibitor migrating at 115, 96, and 209-225 kDa, respectively (Fig. 1). However, C1-Inh consumption and degradation was increased in all of the inflammatory disorders examined in comparison to normal plasma (Fig. 1). This increase in Cl-Inh consumption was evident in the increased amount of cleaved and/or complexed inhibitor present. The pattern of cleavage found in patients with ARDS, for example, indicates considerable degradation of $\mathrm{Cl}$-Inh in vivo. This increased consumption of $\mathrm{Cl}$-Inh is probably a result of the increase in proteolytic activity associated with each of the inflammatory conditions.

$\mathrm{Cl}$-Inh and plasmin were purified and incubated together and it is notable that the successful isolation of undegraded $\mathrm{Cl}$-Inh requires the early removal of plasminogen $(17,18)$. SDSPAGE analysis of the C1-Inh/plasmin interaction revealed a decrease in the amount of $115-\mathrm{kDa}$ Cl-Inh, new C1-Inh derivatives at 96 and 83 $\mathrm{kDa}$, and barely detectable amounts of high molecular mass complexes at $209 \mathrm{kDa}$ and $198 \mathrm{kDa}$ (Fig. 2). Thus the main species generated when normal C1-Inh interacts with plasmin migrated at 96 and $83 \mathrm{kDa}$. This is similar to the degraded forms of $\mathrm{Cl}$-Inh circulating in the plasmas of patients with inflammatory disorders (Fig. 1).

It has been previously shown that plasmin generates two derivatives of $\mathrm{Cl}$-Inh migrating at approximately $96 \mathrm{kDa}$, only one of which retained functional activity $(12,14)$. The $83-\mathrm{kDa}$ species has also been shown to be functionally inactive as it does not bind to activated Cls (14). Therefore, the major derivatives from the interaction between plasmin and $\mathrm{Cl}$-Inh are inactivated $\mathrm{Cl}$-Inh molecules. Further investigations of this interaction were aimed at identifying the precise cleavage events occurring. The strategy employed to identify cleavage sites was to isolate the peptides generated from C1-Inh by plasmin, perform amino acid sequence analysis of the isolated peptides, and in this way locate the precise cleavage sites on the C1-Inh molecule. The peptides generated from $\mathrm{Cl}$-Inh were successfully isolated by reverse phase chromatography (HPLC) (Fig. 4, Table 1). Plasmin cleaves C1-Inh in a very specific manner at 1 arginine residue and 9 lysine residues (Fig. 5). Even under limiting conditions, plasmin generates many peptides from C1-Inh. All of the cleavage sites are at either lysine or arginine residues, although there is a strong preference for lysine. This is in keeping with the known amino acid target preference of plasmin. However, it is striking that the reactive site (Arg 444-Thr 445) $(27,28)$ located by other studies with $\mathrm{Cl}-\mathrm{Inh} / \mathrm{Cls}$ or Cl-Inh/plasma kallikrein, was not cleaved by plasmin under these conditions. This further reinforces the observations from the SDS-PAGE analysis (Fig. 4) that a minimal amount of plasmin is engaged and captured by $\mathrm{Cl}$-Inh at its reactive site.

Spectroscopy indicates that large parts of the native serpin fold exist in a stressed state, and that cleavage of the reactive site loop relieves this general stress (29). It is of interest that most plasmin cleavage sites occur close to the reactive site loop in the native protein (Fig. 6A). Such cleavages would be expected to affect the integrity of the serpin fold by disruption of the $\beta$ sheets $B$ and $C$ and the loops connecting these (Table 1), thereby releasing stress in the native inhibitor. The central $\beta$ sheet $A$ is not directly affected by plasmin. The $\mathrm{Cl}$-Inh model offers an explanation of the sequential effects of $\mathrm{Cl}$-Inh cleavage on its physiological activity. If the first two cleavages occur at sites 1 and 2 (Table 1 ), this releases a peptide Gly195-Lys284 which encompasses one-half of $\beta$ sheet A (Fig. 6B, yellow), 
generating a $96-\mathrm{kDa}$ cleavage product. If this peptide remained in place on $\mathrm{C} 1$-Inh, $\beta$ sheet $\mathrm{A}$ would continue to act as the receptor of the reactive site loop after its cleavage and the activity of C1-Inh could be maintained. This may account for the finding of a functional $96-\mathrm{kDa}$ cleavage product. If cleavages occur between sites 2 and 10 (Table 1 ), the integrity of $\beta$ sheets $\mathrm{B}$ and $\mathrm{C}$ will be disrupted (Fig. 6B, purple), and this will have more severe effects on the physiological activity of Cl-Inh. This cleavage will ultimately lead to the generation of a C1-Inh cleavage product of $83 \mathrm{kDa}$.

The $\mathrm{Cl}$-Inh model also offers an explanation for the location of the plasmin cleavage sites. All the cleavage sites are distant from the heavily glycosylated $\mathrm{N}$-terminal domain of $\mathrm{Cl}$-Inh (Fig. 6A). The position of the $\mathrm{N}$-terminal domain is defined by covalent links to the serpin fold at His 141, Cys182, and Cys406, and is positioned at the end of the serpin fold away from the plasmin cleavage sites (20). The plasmin cleavage sites are distant from all three glycosylation sites at Asn216 and Asn231 at the end of the fold furthest from the reactive site, and also from Asn330 in the central region of the fold. The resulting steric hindrance offered by these four groups would direct plasmin activity toward the reactive site loop region at the other end of the serpin fold as depicted in Fig. 6.

The results of the studies on patients' plasma show that degradation of $\mathrm{Cl}$-Inh is a feature of several inflammatory situations. Although there are apparently large amounts of native $\mathrm{Cl}$-Inh circulating in each of the disorders examined, local degradation of $\mathrm{Cl}$-Inh could lead to a loss of functional C1-Inh activity at the site of inflammation. It is also confirmed that degradation of C1-Inh can readily be accomplished in vitro by plasmin, an enzyme activated during many inflammatory disorders. In addition, the pattern of $\mathrm{C} 1$-Inh degradation in vivo is very similar to that occuring with plasmin in vitro. Furthermore, the isolation of uncleaved $\mathrm{Cl}-\mathrm{Inh}(115 \mathrm{kDa})$ from plasma requires the early removal of plasmin, and the pattern of $\mathrm{C} 1$-Inh cleavage (96 and 83 $\mathrm{kDa}$ ) produced by plasmin has not been reported following incubation with other proteases. Although Cl-Inh is not thought to be an important inhibitor of plasmin in vivo, it can readily be inactivated by plasmin.

Other studies have suggested that additional enzymes such as neutrophil elastase may also be responsible for the degradation of $\mathrm{Cl}$-Inh (30-
32). These results raise intriguing possibilities with regard to the failure of the control of proteolysis occurring in inflammatory disorders. The results also suggest that specific treatment strategies aimed at either increasing serpin activity or diminishing protease action may offer an effective alternative therapeutic approach. In support of this, studies of endotoxin-induced ARDS have shown that $\mathrm{C} 1$-Inh infusion prevented the development of ARDS in animal models $(33,34)$. Furthermore, purified preparations of protease inhibitors have proved to be effective therapy for some of the manifestations of fulminant sepsis in human trials (35).

It has also been known for some time that the anti-plasmin agent epsilon-aminocaproic acid and its analogue tranexamic acid are effective in preventing attacks of edema in Cl-Inhdeficient patients (10). Although these agents are potent inhibitors of plasmin and the fibrinolytic pathway, the precise mechanism by which they attenuate attacks of angioedema is unknown (10). However, activation of the fibrinolytic, complement, and contact phase of blood coagulation has been documented during attacks of edema in Cl-Inh-deficient patients and it has been suggested that anti-plasmin agents exert their effect by directly inhibiting plasmin (3638). It has also been shown that a critical level of $\mathrm{C} 1$-Inh is necessary to prevent attacks of angioedema (39). As our results indicate that plasmin cleaves $\mathrm{C} 1$-Inh very effectively, it is probable that in situations of $\mathrm{Cl}$-Inh deficiency, activation of plasmin may locally degrade $\mathrm{Cl}$-Inh and diminish the quantity of functional $\mathrm{Cl}$-Inh available, thus predisposing to attacks edema. Therefore, anti-plasmin agents may be effective by blocking degradation of C1-Inh by plasmin.

In summary, it has been shown that high levels of inactivated $\mathrm{Cl}$-Inh, a pivotal inhibitor of the contact phase of inflammation, circulate in patients with a variety of inflammatory disorders. It has also been shown that plasmin rapidly degrades $\mathrm{Cl}$-Inh in vitro in a way very similar to that observed in inflammatory disease. We postulate that serpin degradation by proteases may be an important event furthering tissue damage in many common disorders. These findings provide an explanation for the efficacy of anti-plasmin agents in $\mathrm{Cl}$-Inh deficiency disorders and they also have important implications for the design of therapeutic regimes in inflammatory diseases. 


\section{ACKNOWLEDGMENTS}

S. J. P. thanks the Wellcome Trust and the Royal Society for financial support.

\section{REFERENCES}

1. Rubin E, Farber JL (eds). (1988) Pathology. J. B. Lippincott, Philadelphia, pp. 34-1393.

2. Bode W, Huber R. (1992) Natural protein proteinase inhibitors and their interaction with proteinases. Eur. J. Biochem. 204: 433451.

3. Travis J, Salvesen G. (1983) Human plasma proteinase inhibitors. Annu. Rev. Biochem. 52: 655-709.

4. Carrell RW, Boswell DR. (1986) Serpins: The superfamily of plasma protease inhibitors. In: Barrett AJ, Salvesen G (eds). Proteinase Inhibitors. Research Monographs in Cell and Tissue Physiology, Vol. 12. Elsevier, Amsterdam, pp. 403-420.

5. Davis III, AE. (1988) Cl-Inhibitor and hereditary angioneurotic edema. Annu. Rev. Immunol. 6: 595-628.

6. Heidtmann H, Travis J. (1986) Human $\alpha$-1proteinase inhibitor. In: Barrett AJ, Salvesen G (eds). Proteinase Inhibitors. Research Monographs in Cell and Tissue Physiology Vol. 12. Elsevier, Amsterdam, pp. 441-455.

7. Miura O, Hirosawa S, Kato A, Aoki N. (1989) Molecular basis for congenital deficiency of $\alpha$-2-plasmin inhibitor. J. Clin. Invest. 83: 1598-1604.

8. Beresford CH, Owen MC. (1990) Antithrombin III. Int. J. Biochem. 22: 121-128.

9. Sellar GC, Whitehead AS. (1993) The acute phase response and major acute phase proteins in early host defense. J. Biomed. Sci. 4: 1-9.

10. Kerr MA, Yeung-Laiwah AAC. (1986) C1inhibitor deficiency and angio-oedema. In: Whaley $\mathrm{K}$ (ed). Complement in Health and Disease. MTP Press, Lancaster, U.K., pp. 53-78.

11. Gaffney PJ. (1993) Fibrinolysis. In: Bloom $\mathrm{AL}$, Thomas DP (eds). Haemostasis and Thrombosis. Churchill Livingstone, Edinburgh, pp. 223-244.

12. Harpel PC, Cooper NR. (1975) Studies on human plasma $\mathrm{Cl}$ inactivator-enzyme interactions. J. Clin. Invest. 55: 593-604.

13. Donaldson VH, Harrison RA, Rosen FS, Bing DH, Kindness G, Canar J, Wagner CJ, Awad S. (1985) Variability in purified dysfunc- tional $\mathrm{Cl}$-inhibitor proteins from patients with hereditary angioneurotic edema. J. Clin. Invest. 75: 124-132.

14. Jackson J, Sim RB, Whaley K, Feighery C. (1989) Autoantibody facilitated cleavage of Cl-Inhibitor in autoimmune angioedema. J. Clin. Invest. 83: 698-707.

15. Wallace EM, Feighery C, Jackson J. (1996) A solid phase antibody capture assay for the measurement of $\mathrm{Cl}$-inhibitor consumption in vivo. Scand. J. Clin. Lab. Invest. 56: 1-9.

16. Laemmli UK. (1970) Cleavage of structural proteins during the assembly of the head bacteriophage T4. Nature 227: 680-683.

17. Sim RB, Reboul A. (1981) Preparation and properties of human $\mathrm{Cl}$-inhibitor. Methods Enzymol. 80: 43-54.

18. Harrison RA. (1983) Human Cl-inhibitor: Improved isolation and preliminary structural characterisation. Biochemistry 22: 50015007.

19. Deutsch DG, Mertz ET. (1970) Plasminogen: Purification from human plasma by affinity chromatography. Science 170: 1095-1096.

20. Perkins SJ, Smith FS, Amatayakul S, Ashford D, Rademacher TW, Dwek RA, Lachmann PJ, Harrison RA. (1990) The two domain structure of the native and reaction centre cleaved forms of $\mathrm{Cl}$-inhibitor of human complement by neutron scattering. $J$. Mol. Biol. 214: 751-763.

21. Arlaud GJ, Sim RB, Duplaa AM, Colomb MG. (1979) Differential elution of Clq, Clr and $\mathrm{Cls}$ from human $\mathrm{Cl}$ bound to immune aggregates. Use in the rapid purification of Cl subcomponents. Mol. Immunol. 16: 445450.

22. Perkins SJ. (1993) Three-dimensional structure and molecular modeling of $\mathrm{Cl}$-inhibitor. Behring Inst. Mitteil. 93: 63-68.

23. Laskowski RA, McArthur MW, Moss DS, Thornton JM. (1993) PROCHECK-A program to check the stereochemical quality of protein structures. J. Appl. Crystall. 26: 283291.

24. Lee B, Richards FM. (1971) The interpretation of protein structures: Estimation of static accessibility. J. Mol. Biol. 55: 379-400.

25. Bock SC, Skriver K, Nielson E, Thogersen $\mathrm{H}-\mathrm{C}$, Wiman B, Donaldson VH, Eddy RL, Marrinan J, Radziejewska E, Huber R, Shows TB, Magnusson S. (1986) Human Clinhibitor: Primary structure, cDNA cloning, and chromosomal localisation. Biochemistry 25: $4292-4301$. 
26. Harris E. (1993) Etiology and pathogenesis of rheumatoid arthritis. In: Kelly H, Harris E, Ruddy S, Sledge C (eds). Textbook of Rheumatology. W. B. Saunders, London, pp. 883873.

27. Salvesen GS, Catanese JJ, Kress LF, Travis J. (1985) Primary structure of the reactive site of human Cl-inhibitor. J. Biol. Chem. 260: 2432-2436.

28. Patson PA, Gettins P, Beecham J, Schapira M. (1991) Mechanism of serpin action: That $\mathrm{Cl}$ inhibitor functions as a suicide substrate. Biochemistry 30: 8876-8882.

29. Perkins SJ, Smith KF, Nealis AS, Haris PI, Chapman D, Bauer CJ, Harrison RA. (1992) Secondary structure changes stabilise the reactive-centre cleaved form of SERPINs: A study by ${ }^{1} \mathrm{H}-\mathrm{NMR}$ and Fourier transform infra-red spectroscopy. J. Mol. Biol. 228: 12351254.

30. Brower MS, Harpel PC. (1982) Proteolytic cleavage and inactivation of $\alpha_{2}$-plasmin inhibitor and $\mathrm{Cl}$ inactivator by human polymorphonuclear leukocyte elastase. J. Biol. Chem. 257: 9849-9854.

31. Knauper V, Triebel S, Reinke H, Tschesche H. (1991) Inactivation of human plasma C1inhibitor by human PMN leucocyte matrix metalloproteinases. FEBS Lett. 290: 99-102.

32. Schoenberger OL, Sprows JF, Schechter NM, Cooperman BS, Rubin H. (1989) Limited proteolysis of $\mathrm{Cl}$-inhibitor by chymotrypsinlike proteinases. FEBS Lett. 259: 165-167.

33. Guerrero R, Velasco F, Rodriguez $M$, Lopez A, Rojas R, Alvarez MA, Villabis R, Rubio V,

Communicated R. Bucala. Accepted April 17, 1997.
Torres A, del Castillo D. (1993) Endotoxininduced pulmonary dysfunction is prevented by Cl-esterase inhibitor. J. Clin. Invest. 91: 2754-2760.

34. Dickneite G, Seiffge D. (1996) Efficacy of $\mathrm{Cl}$-inhibitor on capillary leakage and septic shock in the rat. In: Faist E, Baue AE, Schildberg FW (eds). Immune Consequences of Trauma, Shock and Sepsis. Mechanistic and Therapeutic Approaches. Pabst Science Publications, Berlin, pp. 44-50.

35. Kitchens C. (1995) Disseminated intravascular coagulation. Curr. Opin. Haematol. 2: 402406.

36. Cugno $M$, Nuijens J, Hack E, Eerenberg A, Frangi D, Agostoni A, Cicardi M. (1990) Plasma levels of $\mathrm{Cl}$ inhibitor complexes and cleaved $\mathrm{Cl}$ inhibitor in patients with hereditary angioneurotic edema. J. Clin. Invest. 85: 1215-1220.

37. Cugno $M$, Hack CE, deBoer JP, Eerenberg JM, Agostoni A, Cicardi M. (1993) Generation of plasmin during acute attacks of hereditary angioedema. J. Lab. Clin. Med. 121: $38-43$.

38. Cugno M, Cicardi M, Agostoni A. (1994) Activation of the contact system and fibrinolysis in autoimmune acquired angioedema: A rationale for prophylactic use of tranexamic acid. J. Allergy Clin. Immunol. 93: 870876.

39. Madalinski K, Sabbouh K, Chorazykiewicz M, Gregorek H. (1991) C1-inhibitor defect as an example of deficiency disease. Immunol. Invest. 20: 133-141. 